\title{
Research on Effective Cultivation Mechanisms of Professional Ethics of Young Teachers in Universities
}

\author{
Shanshan Song \\ Eastern Liaoning University, Dandong, 118003, China
}

\begin{abstract}
From the perspective of the cultivation of professional ethics of young teachers in universities and according to the distinction degree of former and latter moral behaviors and the mobilization and excitation degree of moral development potential, this paper establishes the effective standard of professional ethics cultivation of young teachers in universities and interprets the effective cultivation mechanisms of professional ethics of young teachers in universities. We validate the professional ethics cultivation of young teachers in universities through the models of narrative inquiry, action research and ethnographic study to enhance the effectiveness of the cultivation of university young teachers' occupation moral.

Keywords:young teachers, professional ethics cultivation, effective mechanism

According to the different areas in people's lives, the moral can be divided into social morality, private moralityand professional ethics. Teachers' professional ethics refers to the sum of the stable moral concepts, behavior norms and moral qualities formed by teachers in the process of education. The focus of this paper is the combination of morality, development level and characteristics of the young college teachers.In the process of moral cultivation, we explore the individual moral development rules, to explore effective ways to enhance the moral quality and means. According to the social psychology and age stages, the young teachers in universities refer to the teachers work in ordinary colleges and universities as a teaching and research work whose ages are underforty.
\end{abstract}




\title{
1. Establishment of effective standard of professional ethics cultivation of young teachers in universities
}

\author{
1.1Judgment from distinction degree according to former and latter moral \\ behaviors
}

One of the effective standards of moral cultivation is to distinguish the moral behavior before and after the moral analysis, and analyze the change of the moral behavior in the individual. If to improve or change the previous anomie behavior, we identified the moral cultivation of "effective"; if there is no improvement or change the previous anomie behavior, or more extreme anomie behavior, we identified the moral cultivation of "invalid". This requires that the moral development practitioners in the process of moral development, in order to avoid the absolute evaluation of the end to face the growth of individuals from the perspective of development to focus on the positive role of moral cultivation of individual morality.

The phase of the moral cultivation of the original object level of moral cognition and moral behavior analysis, set the development of a reasonable range, the level of the category of presupposition is the main task to enhance the moral cultivation, according to moral cultivation after the implementation of moral progress degree of the object level of moral to moral judgment is valid. We say that in the original level of moral development has been raised, it can be identified that the process of moral development is true and effective. It is also necessary to distinguish between the effect of moral cultivation and the growth of individuals who do not rely on external forces. Due to the irreversibility of life and the characteristics of a single development, the distinction between the two needs to be tested by time. In addition, the highest realm of morality is to no trace of the way into the life of the individual, to lead and watch the attitude of moral cultivation process. It does not damage the natural growth of the individual, not subjective human interference. Therefore, a bit of progress and continuous fermentation is one of the effective standards of moral interpretation.

Progress is visible through the change of moral behavior in moral development. In contrast, the moral cultivation of various moral process constitute links with the degree of cooperation between the elements is more important, because the coordination between the various elements of good and bad, is directly related to the power and potential of individual moral development. Good coordination, indicating that the process of moral development in the various nodes of the objective in place; the coordination is not good, that the process of moral development is not yet implemented. Of course, in terms of the complex influence factors, we increase the difficulty of coordination constitute various internal moral elements, which is the main "bottleneck" of the development of moral education. The moral cultivation is the priority among priorities of work. Therefore, it is not unreasonable for us to take the degree of coordination as one of the evaluation standards. 


\subsection{Judgment from mobilization and excitation degree of moral development potential}

The mobilization and stimulation of the potential of moral development is also reflected in the active and passive relationship of individual participation in moral development. If individuals actively participate in moral cultivation, moral cultivation attractive; if the individual passive participation of moral cultivation, especially after the participation in the form of a period of time, also appeared the antagonism, the moral content, method, way choice is not attractive enough, need to continue efforts. In the results of the determination and evaluation, the moral cultivation can form moral habits, and gradually transformed into the external lead in the context of self-determination will only generate. We take an external in the formation of moral habits and the formation of a mechanism for the formation of internal independent benign mechanism to determine the effectiveness of moral development.

\section{Interpretation of effective cultivation mechanisms of professional ethics of young teachers in universities}

The application of the effective mechanism of college young teachers' professional ethics should be carried out under the premise of respecting the basic law of moral cultivation. First of all, we follow the subject and object of interaction rules, adhere to the moral cultivation and moral cultivation process interactive implementation of unified leading principle, realize the benign interaction between the two sides positive; secondly, follow the rules of the development of progressive stage, characteristic, according to different stages of teaching; to follow the standard combination, guide individuals and groups to develop, and gradually mutation of the objective law and guidance, in accordance with the law of effectiveness to enhance the moral cultivation. At the same time, mechanism of the interaction between morality, society, schools and families highlight the "three effect connection", combining the interaction and linkage, by mutual development for security mechanism of multi-dimensional interaction. In addition, there are some specific forms, such as the formation mechanism of internalization, the evaluation of incentive mechanism, the regulation mechanism and so on. All of these are the core of the development of ethics in the process of the development of the matching deconstruction, and then counterproductive in the process of achieving the goal of moral development. Therefore, the moral cultivation of "effective" mechanism of the interpretation of the scientific grasp of the rules, in the process of interactive generation, according to the comprehensive evaluation results and results of the form generation process. We should determine whether the operation mechanism is effective according to the distinction of "effective" and "invalid" standard.

In addition, construction of the effective mechanism cannot do without the moral cultivation of specific carrier mode, the advantages and disadvantages of the model of moral education evaluation at home and abroad, and with the moral connotation, goal, content, analysis, implementation of mode specific carrier as 
the moral cultivation of moral education mode of self-experience, and the selfexperience type moral education mode of moral reconstruction, the processing field, the formation of independent experiential model of moral education.

\section{Effectiveness validation of professional ethics cultivation of young teachers in universities}

In the field of the cultivation of the professional ethics, the "effectiveness" is often validated from the models of narrative inquiry, action research and ethnographic study.

\subsection{Narrative inquiry}

As a kind of research approach to human experience, the main source of narrative inquiry is Dewey's pragmatism. Narrative inquiry, that is the combination of "narrative" and "inquiry". The "narrative" is directly related to their understanding of the experience, while the "inquiry" indicates that the way they approach the experience is to inquire into the life. Therefore, narrative inquiry emphasizes participation in real life to think, to "experience", to experience the past, present and future exploration to have understanding of others and self and change the status of interest. In this sense, it is a kind of action and practice oriented research, which embodies the practical philosophy of pragmatism and the spirit of life philosophy. Narrative research in moral cultivation process and results, to the narrator's demanding, and in order to guarantee the effect of objective research, its characteristics showed a small range long-term follow-up study, the statement of the results and to determine the effectiveness of the same moral development, is silent and there are no trace of the enlightened mind form. Play a leading role in the long-term development of its behavior norms. The narrative research can be formed by the moral development of the long-term observation of precipitation and feedback system generation. Therefore, narrative research is very important in the validation of the effectiveness of moral development.

\subsection{Action research}

Action theory is the cornerstone of action research. It is defined as "the educational situation of the participants, in order to improve the understanding of social or educational practice in the rational reflection, study of practice and its background of understanding." The original intention of action research is to fill the gap between theoretical research and social practice. Lewin, the father of action research, proposed in 1948 that "the study of published works is incomplete". Action research in the field of moral development needs to be carried out on the basis of the phased implementation. For example, we can develop the WeChat platformaccording to the university teachers' occupation moral action research steps independently develop, through the electronic platform of young university teachers love to build information and news release 
positive energy, in the long-term cognitive moral guidance and interactive discussion, implementation of comprehensive and systematic and effective for young teachers in university moral spirit then, combined with the experience of the release of information, improve the overall moral quality of young teachers in university.

\subsection{Ethnographic study}

Ethnographic study belongs to the field of sociology, which is similar to the field investigation, but is more concerned with the discovery, analysis and solution of the problem in the perspective of anthropology. Ethnography is a researcher to observe and record access, long-term in the field, its core is the object of study and participant observation, including long-term residence, direct contact, repeated observation, inquiry, chattingand a way of collecting data on the state of nature. In the moral cultivation effectiveness verification field, Ethnography methods can further group role transformation, more comprehensive and vivid description of the organization rules and to express their views, in the form of the combination of subjective and objective, scientific breakthroughs in distress, and moral cultivation process, through a thorough analysis on the details of the power. The verification of the moral cultivation of the validity of the method also includes such as observation, experiment, but no matter what or what kinds of research methods. The target should be based on the essence of individual moral cultivation, moral cultivation and consistent effective standard scientific and objective judgmentto promote the moral cultivation effectiveness.

\section{Conclusion}

In a word, the construction of the effective mechanism of college youngteachers' professional ethics is of far-reaching significance. It is one of the important guarantees to promote the harmonious development of the society. The long term mechanism of college young teachers' professional ethics and the overall construction of the stereo evaluation system will be an important issue to promote the effectiveness of the young teachers' professional ethics in the future.

\section{Acknowledgement}

The research work was supported by the Foundation of Humanities and Social Sciences Project in Liaoning Province named "Research on Moral Education Value of Manchu Folk Culture from the Perspective of Intangible Cultural Heritage" (Grant No. W2015164). It was also the periodical result of the "12th Five Year Plan" subject of EducationalScience in Liaoning Province named "Research on Effective Cultivation Mechanisms of Professional Ethics of Young Teachers in Universities" (Grant No. JG15DB134). 


\section{References}

[1]XuQiang, Tang Meili, Yuan Rong, Zhu Enfang, Research on the Current Situation and Countermeasures ofYoung Teachers' Professional Ethics in Universities-Take Jiangxi Normal University as an example, Journal of Nanchang Normal University (Comprehensive), 37(3), pp. 84-86, 2016.

[2]Liu Haibo, The Concept and Characters of Teachers' Professional Ethics, Journal of Weinan Normal University, 31(22), pp. 90-96, 2016.

[3]Jin Zhanying, Research on the Normalization of Teacher's ProfessionalEthics Construction in the New Media Era, The Guide of Science and Education, (26), pp. 58-59, 2016.

[4] Ma Hongli, On Professional Ethic Concept and Its Construction StrategyAimed at Teachers'Professional Development, Heilongjiang Researches Oil Higher Education, (8), pp. 57-60, 2016.

[5] Chen Hua, On the Conflict of Humanity Hypothesis between Teacher EvaluationSystem and Teacher's Professional Ethics, Journal of Educational Science of Hunan Norm al University, 13(6), pp. 60-64, 2014. 